\title{
Identification of molecular markers for the oncogenic differentiation of hepatocellular carcinoma
}

\author{
Gyung-Ran $\mathrm{Yu}^{1}$, Seong-Hun Kim ${ }^{1}$, Seon-Hwa Park', \\ Xiang-Dan Cui ${ }^{1}$, Dong-Yuan $\mathrm{Xu}^{1}$, Hee-Chul $\mathrm{Yu}^{2}$, \\ Baik-Hwan $\mathrm{Cho}^{2}$, Young-II Yeom ${ }^{3}$, Sang-Soo Kim ${ }^{4}$, \\ Sang-Bae $\mathrm{Kim}^{4}$, In-Sun $\mathrm{Chu}^{4}$ and Dae-Ghon $\mathrm{Kim}^{1,5}$ \\ ${ }^{1}$ Division of Gastroenterology and Hepatology \\ The Research Institute of Clinical Medicine \\ Department of Internal Medicine \\ ${ }^{2}$ Department of Surgery \\ Chonbuk National University Medical School and Hospital \\ Jeonju 561-712, Korea \\ ${ }^{3}$ Funtional Genomics Research Center \\ ${ }^{4}$ Korean Biolnformation Center \\ Korea Research Institute of Bioscience and Biotechnology \\ Daejeon 305-806, Korea \\ ${ }^{5}$ Corresponding author: Tel, 82-63-250-1681; \\ Fax, 82-63-254-1609; E-mail, daeghon@ chonbuk.ac.kr
}

Accepted 20 August 2007

Abbreviations: AFP, $\alpha$-fetoprotein; GI/II, Edmondson grade I/ll; GIII/IV, Edmondson grade III/IV; HCC, hepatocellular carcinoma; LC, liver cirrhosis; NT, non-tumor tissues; NC, non-cirrhosis

\begin{abstract}
The aim of this study was to identify molecular markers associated with oncogenic differentiation in hepatocellular carcinoma (HCC). Using an unsupervised clustering method with a cDNA microarray, HCC (T) gene expression profiles and corresponding non-tumor tissues (NT) from 40 patients were analyzed. Of total 217 genes, 72 were expressed preferentially in HCC tissues. Among 186 differentially regulated genes, there were molecular chaperone and tumor suppressor gene clusters in the Edmondson grades I and II (GI/II) subclass compared with the liver cirrhosis (LC) subclass. The Edmondson grades III and IV (GIII/IV) subclass with a poor survival $(P=0.0133)$ contained 122 differentially regulated genes with a cluster containing various metastasis- and invasion-related genes compared with the GI/II subclass. Immunohistochemical analysis revealed that ANXA2, one of the $\mathbf{7 2}$ genes preferentially expressed in $\mathrm{HCC}$, was over-expressed in the sinusoidal endothelium and in malignant hepatocytes in HCC. The genes identified in the HCC subclasses will be useful molecular markers for the genesis and pro-
\end{abstract}

gression of HCC. In addition, ANXA2 might be a novel marker for tumor angiogenesis in HCC.

Keywords: angiogenesis; carcinoma, hepatocellular; cell differentiation; gene expression profiling; tumor markers, biological

\section{Introduction}

Hepatocellular carcinoma (HCC) is a major malignancy with an increasing worldwide incidence (El-Serag and Mason, 1999). HCC ranks fifth in frequency among all malignancies and causes approximately 600,000 deaths annually (Okuda, 2000; Parkin et al., 2005). A lack of molecular markers that can be used to characterize the development, progression, and angiogenesis of this tumor precludes making an effective diagnosis and correct determination of the prognosis. Although a diagnosis of HCC relies on the presence of a liver mass on radiological images, the detection of an elevated serum alpha fetoprotein (AFP) level is the widely used serum marker for both diagnosing and monitoring HCC (Zaman et al., 1985; Lok and Lai, 1989). However, the AFP level has a low sensitivity and specificity. For example, the level can be normal in up to $40 \%$ of HCC patients, particularly during the early stages (Sherman et al., 1995), and there can be elevated AFP levels in patients with cirrhosis or with exacerbations of chronic hepatitis (Di Bisceglie and Hoofnagle, 1989). Several biomarkers, such as des-gamma carboxyprothrombin (DCP), lens cularis agglutinin-reactive AFP, and glypican-3 (GPC3), have yet to be examined for an ability to detect early HCC (Marrero and Lok, 2004). Therefore, there is a need for development of novel biomarkers for both early detection and evaluation of the progression of HCC. Genome-wide microarray analysis offers a systemic approach for obtaining comprehensive information on HCC transcription profiles. Previous studies have used a microarray to address changes in the gene expression patterns of HCC (Okabe et al., 2001; Shirota et al., 2001). However, these reports compared HCC gene expression profiles with profiles of non-tumor tissues and ignored the heterogeous disease state of the non-tumor samples, such as normal, chronic hepatitis, or hepatic cirrhosis. Most tissue speci- 
mens used for analysis were probably of an advanced stage. Therefore, it is possible that most of the changes observed in these lesions did not necessarily imply causality, but were probably secondary. However, there is little knowledge of the molecular nature of early or multistep hepatocarcinogenesis in human HCC, or of the specific genetic changes associated with the oncogenic differentiation of HCC.

Currently, gene expression profiling studies have analyzed global transcript levels in the context of different histological grades and precancerous dysplastic nodules (Sakamoto et al., 1991; Nam et al., 2005), and identified the genes strongly associated with survival to predict the clinical outcome of HCC (Lee et al., 2004). In contrast, the present study, using a modified analytical approach, was designed to search for HCC molecular markers that are confined to two critical steps of HCC development and advancement. To achieve to this end, the genome expression patterns in 40 paired $\mathrm{HCC}$ and corresponding non-tumor samples were first characterized using a pooled normal liver as a reference. Secondly, the gene expression profiles between the genes of the precancerous cirrhosis (LC) subclass and the genes of the well differentiated HCC (Edmondson grade I/II) subclass were compared. In addition, the gene expression signatures between the well differentiated HCC subclass and the poorly differentiated HCC (Edmondson grade III/IV) subclass were characterized. Thirdly, Northern blot analysis was performed to validate the utility of the data. Finally, the ANXA2 expression level was analyzed as a novel marker of angiogenesis in HCC. The identified novel molecules can be used as markers for both diagnosing and monitoring the prognosis of HCC, and as targets for new anticancer management strategies.

\section{Materials and Methods}

\section{Tissue acquisition}

The study protocol conformed to the ethical guidelines of the Institutional Review Board (IRB). Written informed consent was obtained from each patient. The patients were selected and their sera were tested for both HBV and HCV viral markers using a Cobra Core EIA kit (F. Hoffmann-La Roche Ltd., Basel, Switzerland). AFP levels were measured using a Microparticle Enzyme Immunoassay (Abbott, Abbort Park, IL). Paired samples of tumor and corresponding cirrhotic non-tumor tissues were obtained from resected liver specimens of 40 patients with HCC. Histological examination con- firmed the HCC and non-tumor tissues. The extent of the liver disease of each patient was rated according to the histological activity index (HAI), as previously described by Knodell et al. (1981). Total cellular RNA was extracted using a Tri-zole kit (MRC, Cincinnati, OH). The integrity of RNA specimens was verified by gel electrophoresis.

\section{Preparation of fluorescence-labeled cDNA and microarray hybridization}

The cDNA microarrays (14k) used in this study were obtained from 21C Frontier: The Center for Functional Analysis of the Human Genome (Korea Research Institute of Bioscience and Biotechnology, Daejeon, Korea). The microarray slides collectively contained a total of $14 \mathrm{k}$ cDNA clones consisting of 8,159 unique, sequence-verified clones and housekeeping genes. Fluorescence-labeled cDNA probes were generated from $100 \mu \mathrm{g}$ of total RNA from each tumor by oligo(dT)-primed polymerization using SuperScript II reverse transcriptase (Life Technologies, Grand Island, NY). Reactions were carried out in a final volume of $50 \mu \mathrm{l}$. The fluorescent nucleotides Cy5-dUTP and Cy3dUTP (Amersham Pharmacia Biotech, Piscataway, $\mathrm{NJ}$ ) were used at a concentration of $0.2 \mathrm{mM}$. Human reference RNA, which contained the total RNA samples from 6 different normal livers, was used as a reference for the cDNA microarray analysis. Purified and concentrated fluorescencelabeled cDNA samples from the reference and experimental samples were processed using the methodology reported by Chen et al. (2002).

\section{Imaging and image analysis}

Fluorescence intensities generated by either Cy5 or Cy3 immobilized on the target sequences on the microarray slides were measured using a laser confocal microscope scanning system ScanArray 4000XL (GSI Lumonics, Billerica, MA). The fluorescent images of Cy5 and Cy3 were scanned separately and stored for image analysis. Color images were generated by arbitrarily assigning experimental intensity values to the red channel and reference intensity values to the green channel, and vice versa. The signals from each cDNA target immobilized on a microarray slide were localized, and the expression ratio between the experimental and reference signals (Cy5/Cy3 ratio) was determined using ImaGene ${ }^{\mathrm{TM}} 5.2$ software (BioDiscovery, Los Angeles, CA). The fluorescence intensities of Cy 5 and Cy 3 for each target spot were adjusted so that the median Cy5 and Cy3 intensities of all spots on each slide were 
equal.

\section{Data analysis}

Correlations of the intensity values for each cDNA between the HCC and reference tissues were assessed using scatter plots, and a linear relationship was obtained in log space. All the ImaGene files were uploaded into the Liver cancer database (http://expcal.kobic.re.kr:8080/hcc/) of the Korean Biolnformation Center (http://www.kobic.re.kr). All spots with signal intensities of $<50 \%$ of the local background were flagged and eliminated. The data were normalized using print tip loess normalization with the limma in R packages (http://www.r-project. org) using Bioconductor software (http://www. bioconductor.org). Genes with expression values in more than $80 \%$ of all tissues were retained for analysis. A hierarchical clustering algorithm was applied to all tissues and genes using the Pearson uncentered correlation coefficient as a similarity measure with complete linkage clustering using TIGR MultiExperiment Viewer (version 3.11) software (Dudoit et al., 2003). A two-sample $t$-test based on 10,000 random permutations in the $R$ packages was used to statistically analyze differentially expressed genes. The $q$-value package of the Bioconductor software was used to calculate $q$-values as a significance measure for the genes. Genes with a $q$-value of $<0.05$ and with a mean difference between two groups of $>1.5$ were selected.

\section{Northern blot analysis}

Samples containing $20 \mu \mathrm{g}$ of either total non-tumor or tumor RNAs were fractionated on $1 \%$ agarose gel containing $2.2 \%$ formaldehyde and $50 \mathrm{mM}$ MOPS, and then transferred to a nylon membrane. The hybridization and washing conditions were the same as those described by Kim et al. (2004). cDNA probes for the genes were obtained from 21C Frontier: The Center for Functional Analysis of the Human Genome (Korea Research Institute of Bioscience and Biotechnology).

\section{Immunofluorescence and immunohistochemistry}

Cells were grown and transfected with either the GFP-tagged ANXA2 expression vector or an empty vector control on glass coverslips. Immunofluorescence was performed as described previously by Kim et al. (2004). Cells were examined under a laser-scanning microscope LCM510 (Carl Zeiss, Jena, Germany). Immunohistochemical staining was performed on formalin-fixed, paraffin-embedded tissue sections. The primary antibodies for ANXA2 (H50; Santa Cruz Biotechnology, Santa Cruz, CA) and CD34 (ICO115, Santa Cruz, CA) were detected using secondary biotinylated antibody and a streptavidin-peroxidase conjugate. For double immunostaining, HRP-conjugated streptavidine staining for ANXA2 was carried out, and the peroxidase activity was detected using the enzyme substrate 3 amino-9-ethyl carbazole. Sequential alkaline phosphatase (AP)-conjugated streptavidine staining for CD34 was visualized with the bromochloroindoylphosphate/nitrobluetetrazolium (BCIP/NBT) chromogen substrate, according to the manufacturer's instructions.

\section{Quantification and statistical analysis}

Autoradiographs of Northern hybridizations were scanned using a LAS3000 system (Fuji Photo Film, Tokyo, Japan), and densitometric data were analyzed. Differences in the gene expression levels between the groups were also calculated by normalizing the levels against the $18 \mathrm{~S}$ expression level. All data were entered into Microsoft Excel 5.0, and GraphPad Software was used to analyze survival where appropriate. $P$ values of $<0.05$ were considered significant.

\section{Results}

\section{Gene expression patterns distinguish subclass $\mathrm{GI} / \mathrm{II}$ from subclass LC by hierarchical clustering of HCC and non-tumor liver tissues}

Using cDNA microarray analysis, 40 tumors and corresponding non-tumor tissues were compared against a pool of 6 normal liver tissues. We selected all genes with less than $20 \%$ missing values and SD >0.5. The unsupervised hierarchical clustering analysis of all the tissues was based on the similarity of the expression patterns for all genes (Figure 1A). All the tissue samples, except for two samples, were completely separated into the two main groups of non-tumor liver tissues (NT) and tumor tissues (T). Four distinctive clusters of genes were identified according to their delineation using the hierarchical clustering dendrogram. In the two major sample clusters, one representing $\mathrm{HCC}$ and the other representing nontumor tissues, genes with a $q$-value of $<0.05$ and with a mean difference of $>1.5$ between the two groups were selected. Of these 217 genes, 72 were expressed preferentially in the HCC tissues compared with the non-tumor tissues. Clustering of the non-tumor liver tissues revealed two subclasses having an association with liver cirrhosis 
(LC), with a few exceptions (Figure 1B). Cluster LC mainly contained samples from cases with liver cirrhosis and pre-cirrhotic septal fibrosis (88\%). Analysis of the HCC cluster data also revealed 2 distinct subclasses among the $40 \mathrm{HCC}$ cases (Figure 1C). These two subclasses exhibited strong associations with the Edmondson grades.
Cluster GI/II was associated with Edmondson grades I and II while cluster GIII/IV was associated with Edmondson grades III and VI. Evidently, genes differentially expressed between the premalignant liver cirrhosis and the well differentiated $\mathrm{HCC}$ act as early diagnostic markers for the onset of HCC, or as a molecular target for the develop-
A

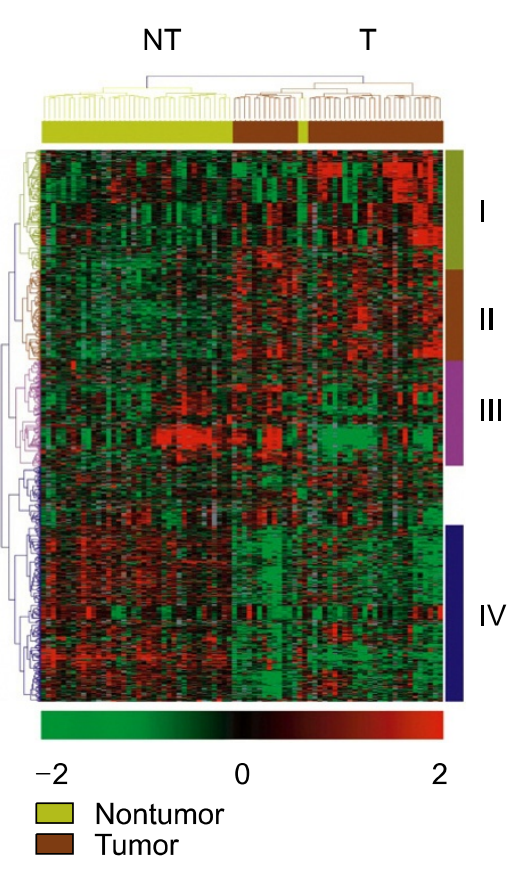

B

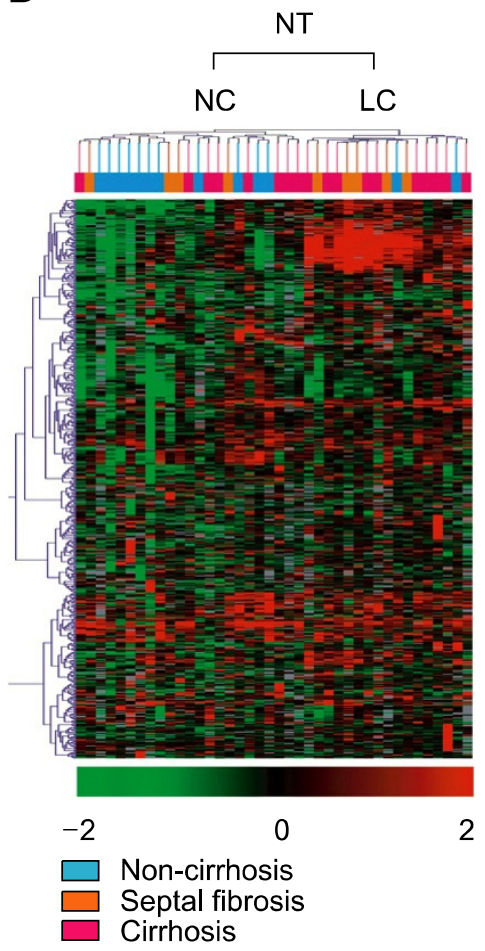

C

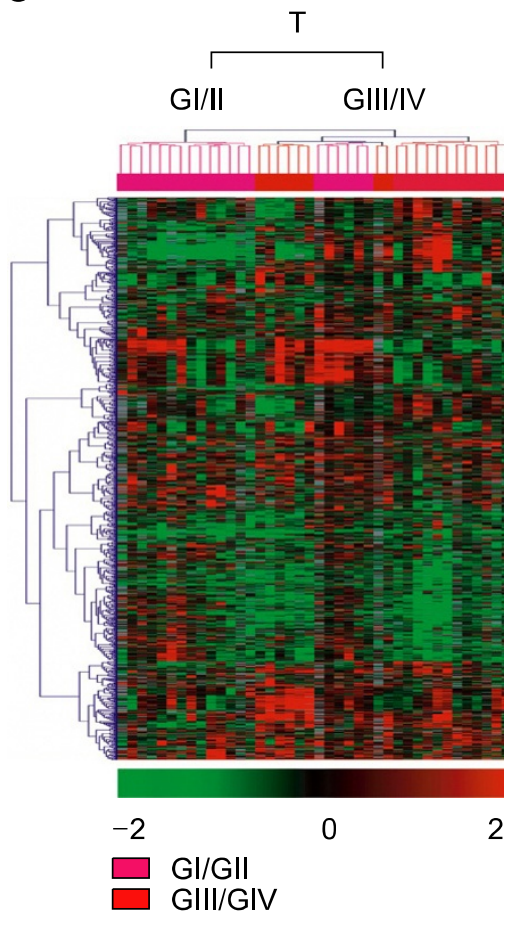

D

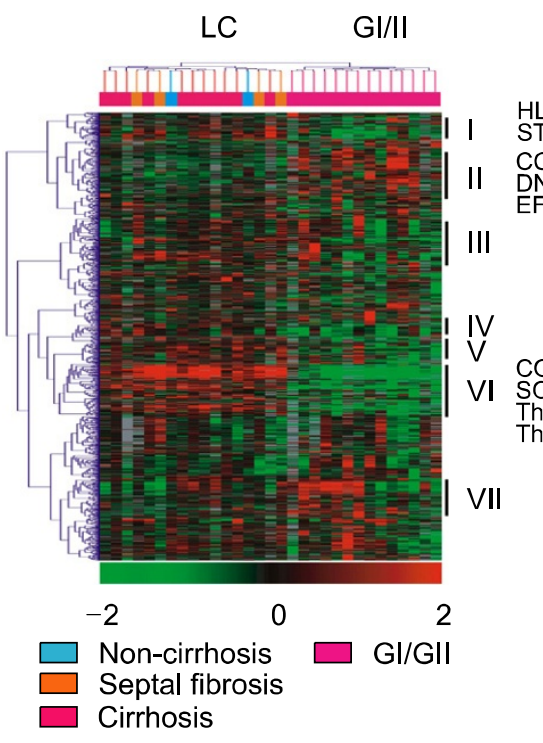

Figure 1. Hierarchical clustering analysis. (A) Unsupervised hierarchical clustering of $40 \mathrm{HCC}$ tumor and 40 matched non-tumor liver tissues separated the samples into two main groups: T and NT. A hierarchical clustering algorithm was applied to all the tissues and genes using the Pearson uncentered correlation coefficient as a similarity measure with complete linkage clustering in TIGR MultiExperiment Viewer (version 3.11) software. Data are presented in matrix format where the columns represent the individual tissues and the rows represent each gene. The red and green colors in the cells reflect high and low expression levels, respectively, as indicated in the scale bar (log2 transformed scale). (B) Unsupervised hierarchical clustering of 40 non-tumor liver tissues separated the samples into LC and NC subclasses. (C) Unsupervised hierarchical clustering of $40 \mathrm{HCC}$ tissues separated the samples into $\mathrm{GI} / \mathrm{II}$ and GIII/IV subclasses. (D) Specific gene subclusters within a hierarchical cluster of the genes differentially expressed in GI/II HCC samples compared with LC tissues. Unsupervised hierarchical clustering of $17 \mathrm{LC}$ and $14 \mathrm{GI} / / \mathrm{HCC}$ samples. Seven gene clusters were differentially expressed between LC and GI/II HCC samples. See supplementary Table 1 for the full list of genes in each cluster. 
ment of HCC. Using unsupervised hierarchical clustering analysis, genes with a $q$-value of $<0.05$ for LC (17 cases) and GI/II (14 cases) were selected. Compared with the liver cirrhosis samples, 51 out of 186 genes were upregulated in GI/II HCC while 135 genes were downregulated. The hierarchical clustering dendrogram identified 7 groups of genes according to the level of delineation. In Figure 1D these groups are listed in each cluster (Supplementary Table 1). The genes in cluster II contained various molecular chaperone genes, and the tumor-related genes were preferentially upregulated in the GI/II subclass, but somewhat downregulated in the LC subclass. Clusters I, III, IV, V and VI contained genes preferentially expressed in subclass LC and downregulated in subclass GI/II HCC. Tumor suppressor and apoptosis-related genes and genes related to the major histocompatibility complex were downregulated in clusters I and VI. The genes in cluster VII were heterogeneously upregulated in GI/II HCC. Liverspecific genes, in addition to genes related to the immune system, were also downregulated in cluster VI.

\section{Gene expression patterns distinguish subclass GIII/IV from subclass GI/II HCC}

Subclass GI/II contained all the Edmondson grades I and II samples (100\%) while subclass GIII/IV contained a higher percentage of Edmondson grades III and IV samples (76.9\%) (Table 1$)$. There was a significant association between the subclass and patient survival. The median survival time in subclass GIII/IV was 15 months, whereas it was 60 months in subclass GI/II. The Kaplan-Meier survival curve indicated a poorer survival $(P=$ 0.01) for GIII/IV HCC patients than for GI/II HCC patients (Figure 2A). Serum AFP levels are believed to be related to the survival of $\mathrm{HCC}$ patients as higher serum AFP levels indicate a poorer survival (Izumi et al., 1992). In contrast, among the clinical indicators of HCC patients, serum AFP levels of $>300 \mathrm{ng} / \mathrm{ml}$ did not show a significant association with survival $(P=0.26)$ (Figure 2B). Subclass III/IV consisted of the two major clusters of mixed (M) and poor differentiation $(P)$. Five groups of genes, identified according to the level of delineation using the hierarchical clustering dendrogram (Figure 3), are listed in each cluster (Supplementary Table 2). Compared with $\mathrm{GI} / \mathrm{II} \mathrm{HCC}, 53$ genes were upregulated in the poor differentiation cluster of subclass GIII/IV while 69 genes were downregulated. Gene cluster I contained the genes significantly upregulated in the $P$ cluster of subclass GIII/IV and downregulated in subclass GI/II. Cluster I contained the tumor- or tumor progression-related genes, in addition to various metastasis- or invasion-related genes. Cluster IV contained the liver specific genes. Cluster V contained the genes substantially upregulated in the $P$ cluster of subclass GIII/IV and downregulated in subclass $\mathrm{GI} / \mathrm{II}$. These results indicate that the genes differentially expressed between subclasses $\mathrm{GI} / \mathrm{II}$ and GIII/IV probably act as molecular markers for HCC progression, including metastasis and invasion.

\section{Verification of HCC-associated gene expression}

The reliability of the microarray data and the robustness of the strategy for identifying genes showing altered expressions were examined. Expression levels of 6 randomly selected upregulated genes and the diubiquitin $D(U B D)$ gene as a positive upregulated control, along with 7 downregulated genes from the 217 genes that were

Table 1. Clinical and pathological features of HCC patients.

\begin{tabular}{|c|c|c|c|}
\hline Variable & Group GI/II & Group GIII/IV & Total \\
\hline No. of patients & 20 & 20 & 40 \\
\hline Male & 16 & 16 & 32 \\
\hline Female & 4 & 4 & 8 \\
\hline \multicolumn{4}{|l|}{ Age } \\
\hline Mean & 52 & 49 & 53.9 \\
\hline SD & \pm 10.7 & \pm 9.5 & \pm 10 \\
\hline \multicolumn{4}{|c|}{$\operatorname{AFP}(>300$ ng/ml) } \\
\hline Positive & 9 & 9 & 18 \\
\hline Negative & 12 & 10 & 22 \\
\hline \multicolumn{4}{|l|}{ Etiology } \\
\hline HBV & 17 & 14 & 31 \\
\hline $\mathrm{HCV}$ & 1 & 3 & 4 \\
\hline Alcohol & 2 & 0 & 2 \\
\hline Unknown & 0 & 3 & 3 \\
\hline \multicolumn{4}{|l|}{ Edmondson grade } \\
\hline I & 2 & 0 & 2 \\
\hline II & 17 & 4 & 21 \\
\hline III & 1 & 10 & 11 \\
\hline IV & 0 & 6 & 6 \\
\hline \multicolumn{4}{|l|}{ Cirrhosis } \\
\hline Cirrhosis & 8 & 11 & 19 \\
\hline Non-cirrhosis & 13 & 8 & 21 \\
\hline Death & 12 & 15 & 23 \\
\hline \multicolumn{4}{|l|}{ Survival (months) } \\
\hline Median & 60 & $15^{\mathrm{a}}$ & 49 \\
\hline Standard error & \pm 8.1 & \pm 6.7 & \pm 10.25 \\
\hline
\end{tabular}

${ }^{\mathrm{a}} P=0.01$ vs Group $\mathrm{GI} / \mathrm{II}$. 
A

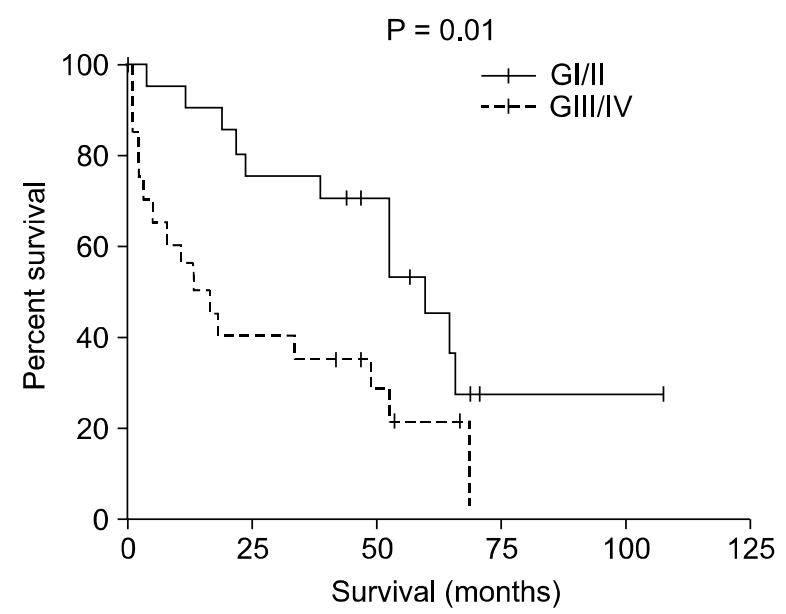

B

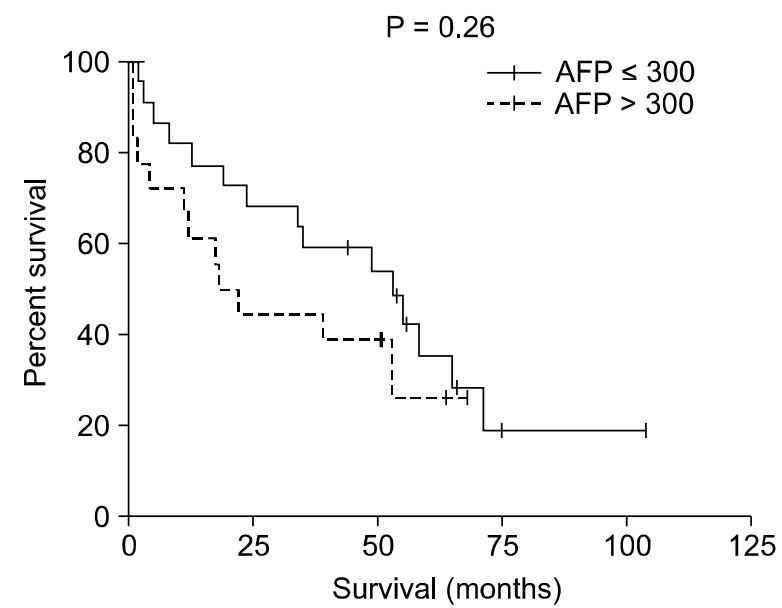

Figure 2. A Kaplan-Meier plot of the overall survival of HCC patients. (A) HCC patients were grouped according to gene expression profiling of GI/II and GII/IV. (B) HCC patients were grouped according to their AFP levels ( > $300 \mathrm{ng} / \mathrm{ml}$ ).

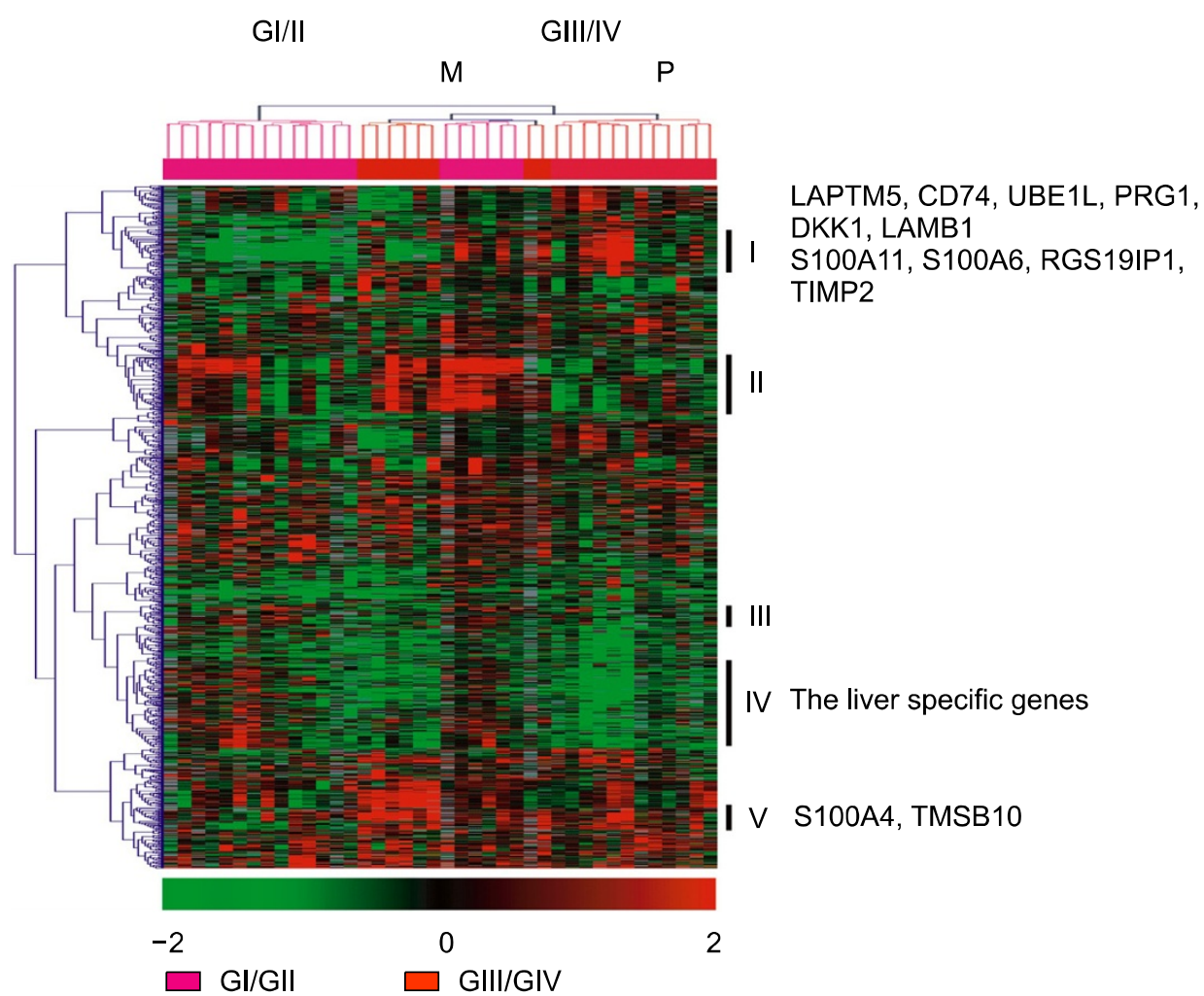

Figure 3. Specific gene subclusters within a hierarchical cluster of differentially expressed genes in subclass GIII/NI compared with subclass GI/II. Unsupervised hierarchical clustering of $14 \mathrm{GI} / \mathrm{II} \mathrm{HCC}$ and 26 GIII/IV HCC samples. Subclass III/IV consisted of the two major clusters of mixed (M) and poor differentiation $(P)$. Five gene subclusters within an unsupervised hierarchical cluster of $\mathrm{Gl} / \mathrm{Il}$ and GIII/IV. See supplementary Table 2 for the full list of genes in each cluster. differently expressed in HCC and non-tumor liver tissues were examined using Northern blot analysis from $15 \mathrm{HCC}$ and corresponding nontumor tissues. These genes represented an independent sample set that had been used in microarray studies (Figure S1). UBD was upregulated in 14 of 15 HCC tissue samples (93.3\%) compared with matched non-tumor tissues. This result is in agreement with the previous report of Lee et al. (2003) in which G22P1 (Ku70) was preferentially overexpressed in 14 of 15 samples (93.3\%) and DSCR1 was differentially underexpressed in all 15 samples (100\%) of HCC tissues compared with non-tumor tissues. The microarray data were further tested by randomly selecting genes that were differentially expressed in GI/II 
HCC and LC tissues and determining the mRNA expression levels of 3 normal liver $(N), 3$ cirrhotic liver (LC), $4 \mathrm{GI} / \mathrm{II} \mathrm{HCC}$, and $4 \mathrm{GIII/IV} \mathrm{HCC} \mathrm{tissues}$ (Figure 4A). GPC3 expression was first examined in the HCC tissues as a positive control because it is overexpressed in HCC (Capurro et al., 2003). GPC3 was substantially overexpressed in the GI/II
HCC tissues compared with the normal liver and LC tissues. The GPC3 expression level was much higher in the GIII/IV HCC tissues than in the GI/II HCC tissues. Ku70, PSMD4, HSPCB, and ATP1B1 were preferentially expressed in the GI/II HCC tissues compared with the normal liver and LC tissues. In contrast, the DUSP6, KPNA4, IGFBP3,

A
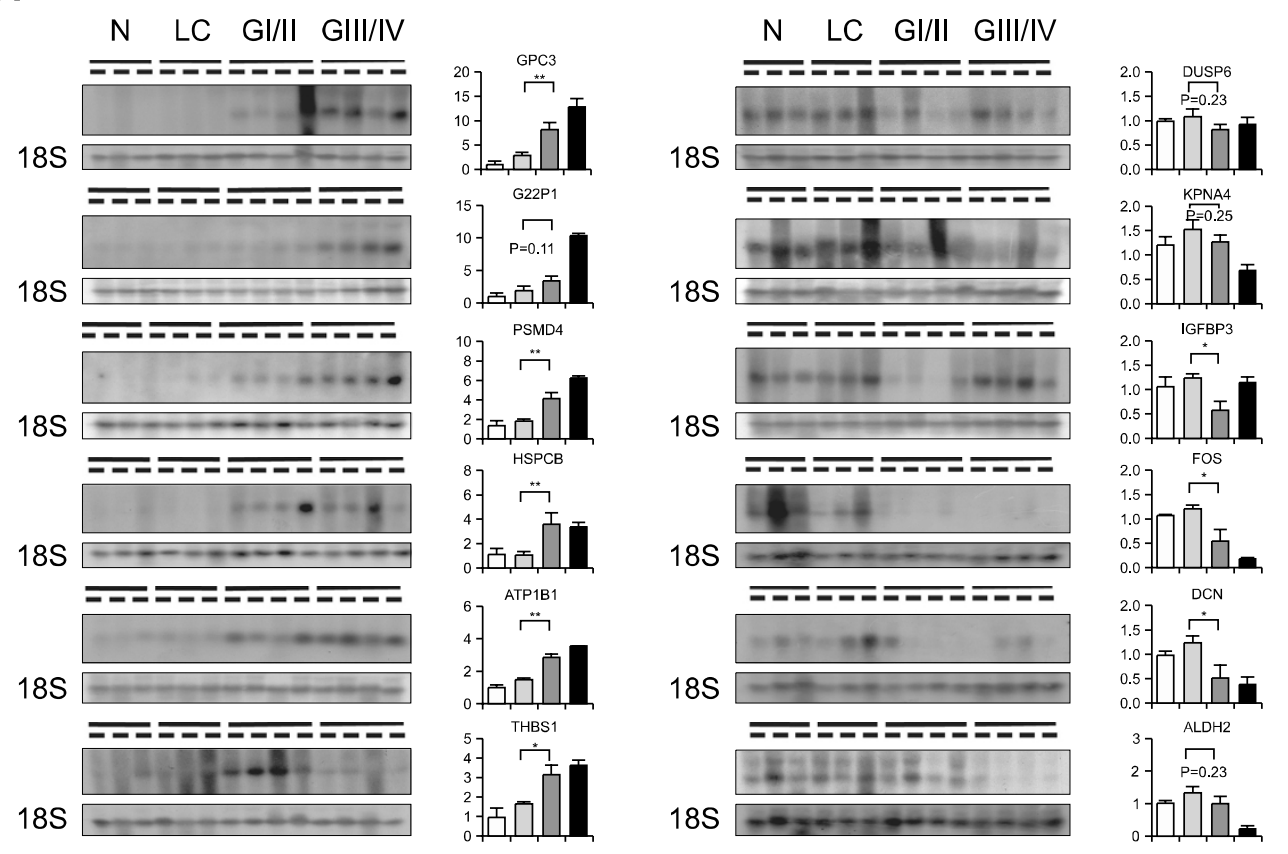

B
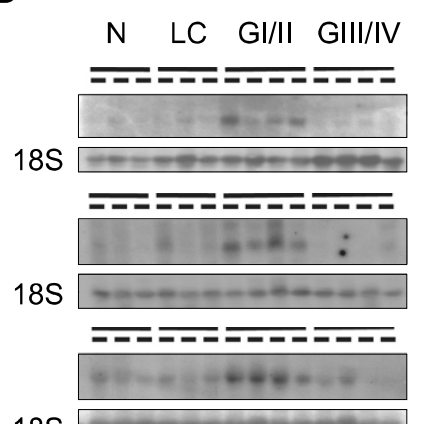

$18 \mathrm{~S}$

$18 \mathrm{~S}$
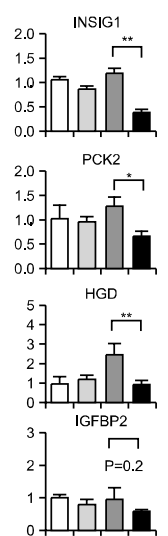

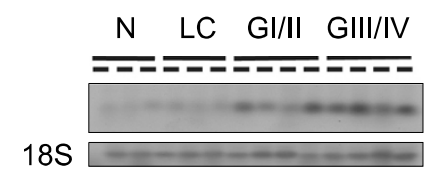

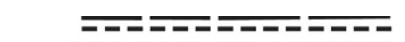

$18 \mathrm{~S}$
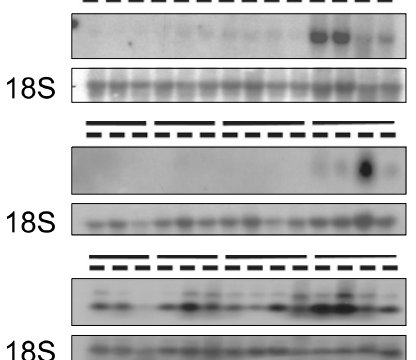
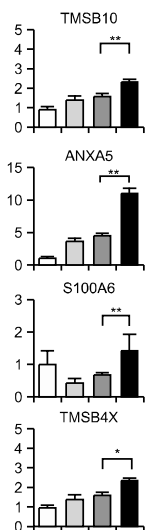

Figure 4. Expression pattern of the genes identified from microarray data. (A) The mRNA expression pattern of the identified genes that were differentially expressed in the GI/II HCC samples compared with LC tissues. Northern blot analysis was performed to analyze 12 genes in 3 normal liver samples (Ns), 3 LC samples, 4 GI/II HCC samples, and 4 GIII/IV HCC samples (left). The levels of gene expression were quantified (right). The vertical bars represent the mean $\pm \mathrm{SD}$. ${ }^{*} P<0.05$. ${ }^{* *} P<0.01$. (B) mRNA expression patterns of the identified genes that were differentially expressed in the GIII/IV HCC samples compared with the GI/II HCC samples (left). The levels of gene expression were quantified by Northern blot analysis of $3 \mathrm{~N}, 3 \mathrm{LC}, 4 \mathrm{GI} / \mathrm{IICC}$, and 4 GIII/IV HCC samples for 12 genes (right). The vertical bars represent the means $\pm \mathrm{SD} .{ }^{*} P<0.05 .{ }^{* *} P<0.01$. 
FOS, and DCN mRNA expression levels were downregulated in the GI/II HCC tissues compared with the LC tissues. The mRNA transcripts of the genes that distinguished between the GIII/IV and $\mathrm{GI} / \mathrm{II} \mathrm{HCC}$ tissues were then validated (Figure 4B). The liver specific genes INSIG1, PCK2, and HGD were downregulated in the GIII/IV HCC tissues compared with the $\mathrm{GI} / \mathrm{II}$ tissues. These transcripts were upregulated compared with the normal liver and cirrhotic tissues. TMSB10, ANXA5, S100A6 and TMSB4X were upregulated in the GIII/IV tissues.

\section{Differential expression of ANXA2 between HCC and non-tumor tissues}

We observed that ANXA2 mRNA was preferentially overexpressed in all $15 \mathrm{HCC}$ tissue samples $(100 \%)$ examined (Figure 5A). Therefore, we examined the ANXA2 expression levels in paraffinembedded tissue sections obtained from 60 samples of HCC and 60 samples of nonmalignant liver tissues (Table 2). Positive staining in the endothelial cells of the sinusoid was observed in 52 of $60(86.7 \%)$ HCC tissues. (Figure 5B, d-h) and in the malignant hepatocytes of 30 of $60(50 \%)$ $\mathrm{HCC}$ tissues (Figure 5B, i and j). Positive ANXA2 immunoreactivity was consistent with the immunoreactivity of CD34 (Figure $5 B, d$, e, and f), which is a neovascularization marker in $\mathrm{HCC}$. This indicates that ANXA2 is probably involved in tumor angiogenesis in HCC. Immunohistochemical staining of ANXA2 was rarely observed in hepatocytes from

Table 2. Immunohistochemistry of ANXA2 in HCC versus nontumor tissues with normal findings, chronic hepatitis, or cirrhosis.

\begin{tabular}{lcc}
\hline \multicolumn{1}{c}{ Tissue } & $\begin{array}{c}\text { No. of } \\
\text { specimens }\end{array}$ & $\begin{array}{c}\text { No. of positive } \\
\text { cases }(\%)\end{array}$ \\
\hline $\begin{array}{l}\text { Non-tumor liver } \\
\text { Hepatocytes }\end{array}$ & 60 & $3(5.0)$ \\
$\quad \begin{array}{l}\text { Sinusoidal endothelial cells } \\
\text { Vascular endothelial cells }\end{array}$ & 60 & $21(35.0)^{*}$ \\
$\quad$ in portal tract & 60 & $59(98.3)$ \\
$\quad$ Bile ducts in portal tracts & 60 & $59(98.3)$ \\
HCC & & \\
$\quad$ Hepatocytes & 60 & $30(50.0)^{\dagger}$ \\
$\quad$ Sinusoidal endothelial cells & 60 & $52(86.7)^{\ddagger}$ \\
\hline
\end{tabular}

${ }^{*}$ Focal immunostaining in $<10 \%$ of the endothelial cells of the sinusoid in chronic hepatitis with or without cirrhosis. Significance was measured using a Chi-square test or a two-tailed Fisher's exact test; a $P$ value of $<$ 0.05 was considered to be significant. ${ }^{\dagger} P<0.01$ versus hepatocytes of non-tumor liver. ${ }^{\ddagger} P<0.01$ versus sinusoidal endothelial cells of non-tumor liver. the 60 non-tumor liver tissues, which included normal, chronic hepatitis, and chronic hepatitis with cirrhosis (Figure $5 \mathrm{~B}, \mathrm{a}, \mathrm{b}$, and $\mathrm{c}$ ) samples. The sinusoidal endothelial cells affected by chronic hepatitis showed no immunostaining or only focal immunostaining for ANXA2, similar to the results for CD34 immunostaining. Positive immunostaining for ANXA2 was always observed in vascular endothelial cells and in the bile duct epithelium in the portal areas of the non-tumor liver tissues (Figure $5 B, c)$. ANXA2 staining was detected in the cytoplasm (Figure 5B, i) and/or along the cytoplasmic membrane (Figure 5B, j) in malignant hepatocytes. Negative immunoreactivity for ANXA2 was observed in metastatic colon cancer to the liver (Figure 5B, k), whereas the granular immunoreactvity of ANXA2 in cholangiocarcinoma cells was detected in the cytoplasm (Figure 5B, I).

\section{Discussion}

Our results revealed that major clusters of both non-tumor and HCC tissues show a degree of heterogeneity within a gene expression profile. These clusters can be subdivided into either NC and LC subclasses in the non-tumor tissues or GI/II and GIII/IV subclasses in the HCC tissues according to histopathological characteristics. In contrast, other studies have reported that two distinct subclasses of HCC are weakly associated with the Edmondson grade according to hierarchical clustering gene expression patterns (Lee et al., 2004). Analysis of the clustered data in the gene expression profiles between the LC and GI/II subclasses revealed that cluster II contained various molecular chaperone genes, including CCT5, HSPCB, CCT3, HSPCA, DNAJB11, HSPB1, and TOMM20, which suggests that proteindamaging stress can contribute to hepatocarcinogenesis. Many key components of the survival and apoptotic pathways are regulated by interactions with molecular chaperones, which are primarily members of the Hsp70 and Hsp90 families (Mosser and Morimoto, 2004). HSP70 (HSPCB) has been reported to be a sensitive marker for the differential diagnosis of early HCC from a precancerous lesion or a non-cancerous liver (Chuma et al., 2003). Cluster II also contained the tumor-related genes EFNA1, MDK, RBM17, FDPS, and $p 8$ and the LASS2 anti-metastasis gene (Ree et al., 1999; Kato et al., 2000; Sampath et al., 2003; Fei et al., 2004; Pilarsky et al., 2004; Nakamura et al., 2005). Clusters I, III, IV, V, and VI contained the genes that were preferentially expressed in subclass LC and downregulated in 
A

$N T$ T T T N T N T N T N T N T N N T N T N T N T N T N T N T N T $--\infty-\infty-\infty-\infty-\infty-\infty$

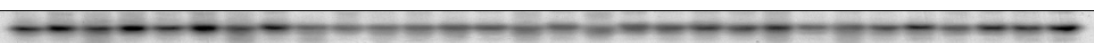

B
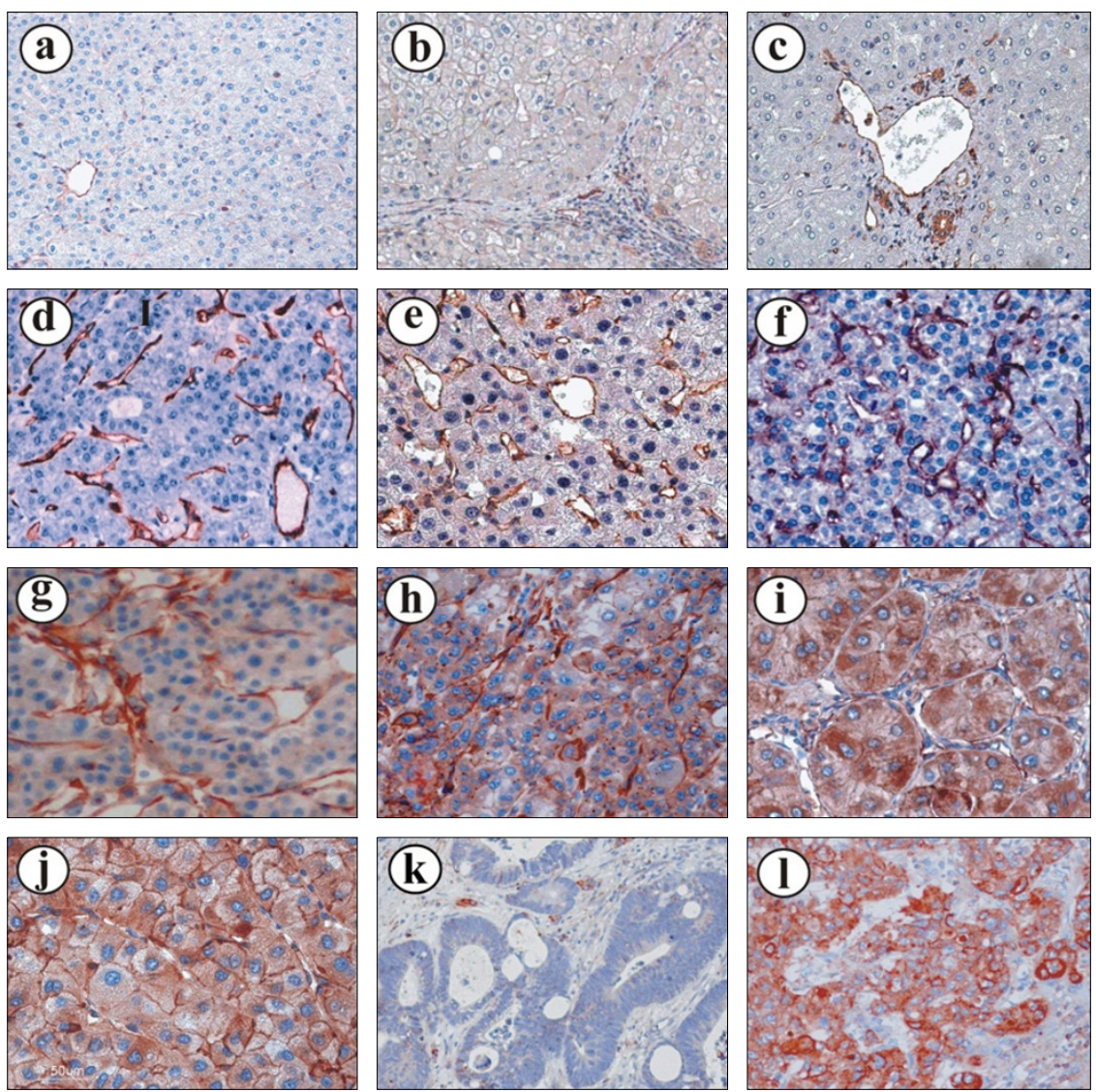

Figure 5. Differentially expressed ANXA2 in HCC samples compared with non-tumor tissues. (A) Northern blot analysis was used to analyze 15 pairs of non-tumor liver $(\mathrm{N})$ and $\mathrm{HCC}(\mathrm{T})$ tissues for the expression of ANXA2 gene. (B) Immunohistochemical staining of human HCC tissue sections using the anti-ANXA2 antibody. (a) Negative immunoreactivity for ANXA2 in the sinusoidal endothelium in a normal liver and positive staining of endothelial cells of a central vein (original magnification; $\times 100$ ). (b) Negative immunoreactivity for ANXA2 in the sinusoidal endothelium within a regenerative (cirrhotic) nodule. Positive ANXA2 immunoreactivity in the vascular endothelium and bile duct epithelium in the portal tracts of cirrhotic liver tissues (original magnification, $\times 100$ ). (c) A high power field of the portal area. Positive ANXA2 immunoreactivity in the vascular endothelium and bile duct epithelium in the portal tracts of non-tumor tissues (original magnification; $\times 200$ ). (d) Positive CD34 immunoreactivity in the sinusoidal and vascular endothelium in GII HCC tissue (original magnification; $\times 200$ ). (e) A strong ANXA2 positive reaction in the endothelial cells of the sinusoids in GI HCC tissues, which is similar to the positive CD34 staining in the tumor endothelium (original magnification; $\times 200$ ). (f) Simultaneous double staining performed with anti-ANXA2 (red) and anti-CD34 (purple-blue). Co-localization of ANXA2 and CD34 immunoreactivity in the endothelial cells in GII HCC tissue (original magnification; $\times 200$ ). $(\mathrm{g})$ and $(\mathrm{h})$ Positive ANXA2 immunoreactivity in the endothelial cells of the sinusoids in GIII and GIV HCC tissues (original magnification; $\times 200$ ). (i) and (j) Heterogeneous immunoreactivity of ANXA2 is observed in the cytoplasm and/or along the cytoplasmic membranes in malignant hepatocytes (original magnification; $\times 200$ ). (k) Negative immunoreactivity for ANXA2 in metastatic colon cancer to the liver (original magnification, $\times 100$ ). (I) Granular immunoreactivity of ANXA2 in cholaniocarcinoma cell cytoplasm (original magnification, $\times 100$ ). 
subclass $\mathrm{GI} / \mathrm{Il} \mathrm{HCC}$. The tumor suppressor and apoptosis-related genes (STAT1, IGFBP7, THY28, and DDB1) (Landberg et al., 2001; Bontron et al., 2002; Jiang et al., 2003; Xi et al., 2006) and the genes related to the major histocompatibility complex (HLA-DRB3, HLA-DPA1, HLA-DRA) were downregulated in cluster I. The genes associated with the immune system were downregulated in cluster VI, which suggests that the deterioration of immune surveillance and apoptosis occurs at an early stage of HCC development. Other tumor suppressor genes, including COPEB, DUSP6, IGFBP3, ZFP36, SOD2, DSCR1, ARHE, and NPDC1 (Buckbinder et al., 1995; Galiana et al., 1995; Zhao et al., 2002; Furukawa et al., 2003; Stoecklin et al., 2003; Reeves et al., 2004; Villalonga et al., 2004; Hampton, 2005), were observed in cluster VI. Altered expressions of the COPEB and IGFBP3 genes have been reported in HCC (Hanafusa et al., 2002; Kremer-Tal et al., 2004).

An analysis of the HCC cluster data revealed that the two distinct subclasses GI/II and GIII/IV are strongly associated with patient survival. Two upregulated gene clusters ( $\mathrm{I}$ and $\mathrm{V}$ ) and 3 downregulated clusters (II, III, and IV) were identified in subclasses GIII/IV of HCC. Cluster I contained the tumor- or tumor progression-related genes LAPTM5, CD74, UBE1L, PRG1, DKK1, and LAMB1 (Shen et al., 1997; Schafer et al., 1998; McLaughlin et al., 2000; Seimiya et al., 2003; Wirths et al., 2003; Hira et al., 2005). Cluster I also contained various metastasis- or invasion-related genes, including S100A11, S100A6, RGS19IP1, and TIMP2 (Weterman et al., 1992; Musso et al., 1997; Awan et al., 2002; Mori et al., 2004). The upregulated metastasis-related gene S100A4 (Garrett et al., 2006) and the tumor-associated gene TMSB10 (Alldinger et al., 2005) were also included in Cluster V. There was no significant association between the etiology of HCC and differential expression of the genes, probably due to the small number of HCC samples derived from etiologies other than HBV.

ANXA2, which is a substrate for kinases and a receptor for the tissue-type plasminogen activator and plasminogen, is believed to be related to the metastasis of various tumors (Hajjar et al., 1994; Tanaka et al., 2004). Our results showed that ANXA2 was upregulated in all HCC tissues, suggesting that ANXA2 plays a role in HCC development and progression. HCC is a typical hypervascular tumor. Therefore, the specificity of the endothelial markers for distinguishing normal sinusoids from sinusoid-like tumor vessels in the liver is essential for describing tumor revasculariza- tion. Angiogenesis of sinusoidal capillarization is usually evaluated by determining the degree of CD34 expression. Our results showed that the immunoreactivity of ANXA2 is an effective method for evaluating the extent of angiogenesis and for distinguishing HCC from non-neoplastic liver tissue. The role of ANXA2 in neovascularization is not completely understood. However, the local plasmin formation induced by the S100A4/annexin II interaction on the surface of the activated endothelium probably contributes to tumor-induced angiogenesis and metastasis (Semov et al., 2005). Therefore, this protein complex might be another attractive target for new anti-cancer and antiangiogenic treatments in $\mathrm{HCC}$ if the treatment strategy is to protect the vascular endothelial cells and the bile ducts in the portal tract. ANXA2 expression in cholangiocarcinoma fails to distinguish cholangiocarcinoma from the normal epithelium of the bile duct because both highly express ANXA2.

Our results indicate that ANXA2 expression might be a novel marker for angiogenesis in HCC. Array-based expression profiling can identify novel molecules to be used as markers for the genesis and progression of $\mathrm{HCC}$, and can provide targets for new anticancer management strategies.

\section{Acknowledgments}

This work was supported by the National R\&D Program for Cancer Control of the Ministry of Health and Welfare (0620220-1), and the 21C Frontier Functional Human Genome Project of the Ministry of Science and Technology (FG06-11-09), Republic of Korea. The authors wish to thank the Korea Basic Science Institute for laser scanning microscopy.

\section{References}

Alldinger I, Dittert D, Peiper M, Fusco A, Chiappetta G, Staub E, Lohr M, Jesnowski R, Baretton G, Ockert D, Saeger HD, Grutzmann R, Pilarsky C. Gene expression analysis of pancreatic cell lines reveals genes overexpressed in pancreatic cancer. Pancreatology 2005;5:370-9

Awan A, Lucic MR, Shaw DM, Sheppard F, Westwater C, Lyons SA, Stern PL. 5T4 interacts with TIP-2/GIPC, a PDZ protein, with implications for metastasis. Biochem Biophys Res Commun 2002;290:1030-6

Bontron S, Lin-Marq N, Strubin M. Hepatitis B virus X protein associated with UV-DDB1 induces cell death in the nucleus and is functionally antagonized by UV-DDB2. J Biol Chem 2002;277:38847-54

Buckbinder L, Talbott R, Velasco-Miguel S, Takenaka I, Faha $B$, Seizinger BR, Kley N. Induction of the growth inhibitor IGF-binding protein 3 by p53. Nature 1995;377:646-9 
Capurro M, Wanless IR, Sherman M, Deboer G, Shi W, Miyoshi E, Filmus J. Glypican-3: a novel serum and histochemical marker for hepatocellular carcinoma. Gastroenterology 2003;125:89-97

Chen X, Cheung ST, So S, Fan ST, Barry C, Higgins J, Lai KM, Ji J, Dudoit S, Ng IO, Van De Rijn M, Botstein D, Brown PO. Gene expression patterns in human liver cancers. Mol Biol Cell 2002;13:1929-39

Chuma M, Sakamoto M, Yamazaki K, Ohta T, Ohki M, Asaka $\mathrm{M}$, Hirohashi S. Expression profiling in multistage hepatocarcinogenesis: identification of HSP70 as a molecular marker of early hepatocellular carcinoma. Hepatology 2003;37:198-207

Di Bisceglie AM, Hoofnagle JH. Elevations in serum alpha-fetoprotein levels in patients with chronic hepatitis $B$. Cancer 1989;64:2117-20

Dudoit S, Gentleman RC, Quackenbush J. Open source software for the analysis of microarray data. Biotechniques 2003;Suppl:45-51

El-Serag HB, Mason AC. Rising incidence of hepatocellular carcinoma in the United States. N Engl J Med 1999;340: 745-50

Fei $P$, Junyu $N$, Jiangfeng $Y$, Jingpin $Y$, Yuping $W$, Zhihui $H$, Jieliang W, Xianglin C, Shaomin Y, Jie Z. Monoclonal antibodies against human tumor metastasis suppressor gene-1 (TMSG-1): preparation, characterization, and application. Hybrid Hybridomics 2004;23:318-25

Furukawa T, Sunamura M, Motoi F, Matsuno S, Horii A. Potential tumor suppressive pathway involving DUSP6/ MKP-3 in pancreatic cancer. Am J Pathol 2003;162:1807-15

Galiana E, Vernier P, Dupont E, Evrard C, Rouget P. Identification of a neural-specific cDNA, NPDC-1, able to downregulate cell proliferation and to suppress transformation. Proc Natl Acad Sci USA 1995;92:1560-4

Garrett SC, Varney KM, Weber DJ, Bresnick AR. S100A4, a mediator of metastasis. J Biol Chem 2006;281:677-80

Hajjar KA, Jacovina AT, Chacko J. An endothelial cell receptor for plasminogen/tissue plasminogen activator. I. Identity with annexin II. J Biol Chem 1994;269:21191-7

Hampton T. Down syndrome protein deters cancer: scientists reveal molecular mechanism. JAMA 2005;293:284-5

Hanafusa T, Yumoto Y, Nouso K, Nakatsukasa H, Onishi T, Fujikawa T, Taniyama M, Nakamura S, Uemura M, Takuma Y, Yumoto E, Higashi T, Tsuji T. Reduced expression of insulin-like growth factor binding protein-3 and its promoter hypermethylation in human hepatocellular carcinoma. Cancer Lett 2002;176:149-58

Hira E, Ono T, Dhar DK, El-Assal ON, Hishikawa Y, Yamanoi $A$, Nagasue $\mathrm{N}$. Overexpression of macrophage migration inhibitory factor induces angiogenesis and deteriorates prognosis after radical resection for hepatocellular carcinoma. Cancer 2005;103:588-98

Izumi R, Shimizu K, Kiriyama M, Hashimoto T, Urade M, Yagi M, Mizukami Y, Nonomura A, Miyazaki I. Alpha-fetoprotein production by hepatocellular carcinoma is prognostic of poor patient survival. J Surg Oncol 1992;49:151-5
Jiang XZ, Toyota H, Yoshimoto T, Takada E, Asakura H, Mizuguchi J. Anti-lgM-induced down-regulation of nuclear Thy28 protein expression in Ramos B lymphoma cells. Apoptosis 2003;8:509-19

Kato M, Shinozawa T, Kato S, Endo K, Terada T. Increased midkine expression in intrahepatic cholangiocarcinoma: immunohistochemical and in situ hybridization analyses. Liver 2000;20:216-21

Kim JH, You KR, Kim IH, Cho BH, Kim CY, Kim DG. Overexpression of the ribosomal protein L36a gene is associated with cellular proliferation in hepatocellular carcinoma. Hepatology 2004;39:129-38

Knodell RG, Ishak KG, Black WC, Chen TS, Craig R, Kaplowitz N, Kiernan TW, Wollman J. Formulation and application of a numerical scoring system for assessing histological activity in asymptomatic chronic active hepatitis. Hepatology 1981;1:431-5

Kremer-Tal S, Reeves HL, Narla G, Thung SN, Schwartz M, Difeo A, Katz A, Bruix J, Bioulac-Sage P, Martignetti JA, Friedman SL. Frequent inactivation of the tumor suppressor Kruppel-like factor 6 (KLF6) in hepatocellular carcinoma. Hepatology 2004;40:1047-52

Landberg G, Ostlund H, Nielsen NH, Roos G, Emdin S, Burger AM, Seth A. Downregulation of the potential suppressor gene IGFBP-rP1 in human breast cancer is associated with inactivation of the retinoblastoma protein, cyclin $E$ overexpression and increased proliferation in estrogen receptor negative tumors. Oncogene 2001;20: 3497-505

Lee CG, Ren J, Cheong IS, Ban KH, Ooi LL, Yong Tan S, Kan A, Nuchprayoon I, Jin R, Lee KH, Choti M, Lee LA. Expression of the FAT10 gene is highly upregulated in hepatocellular carcinoma and other gastrointestinal and gynecological cancers. Oncogene 2003;22:2592-603

Lee JS, Chu IS, Heo J, Calvisi DF, Sun Z, Roskams T, Durnez A, Demetris AJ, Thorgeirsson SS. Classification and prediction of survival in hepatocellular carcinoma by gene expression profiling. Hepatology 2004;40:667-76

Lok AS, Lai CL. alpha-Fetoprotein monitoring in Chinese patients with chronic hepatitis $B$ virus infection: role in the early detection of hepatocellular carcinoma. Hepatology 1989;9:110-5

Marrero JA, Lok AS. Newer markers for hepatocellular carcinoma. Gastroenterology 2004;127(5 Suppl 1):S113-9

McLaughlin PM, Helfrich W, Kok K, Mulder M, Hu SW, Brinker MG, Ruiters $\mathrm{MH}$, de Leij LF, Buys $\mathrm{CH}$. The ubiquitinactivating enzyme $\mathrm{E} 1$-like protein in lung cancer cell lines. Int J Cancer 2000;85:871-6

Mori M, Shimada H, Gunji Y, Matsubara H, Hayashi H, Nimura Y, Kato M, Takiguchi M, Ochiai T, Seki N. S100A11 gene identified by in-house cDNA microarray as an accurate predictor of lymph node metastases of gastric cancer. Oncol Rep 2004;11:1287-93

Mosser DD, Morimoto RI. Molecular chaperones and the stress of oncogenesis. Oncogene 2004;23:2907-18

Musso O, Theret N, Campion JP, Turlin B, Milani S, Grappone 
C, Clement B. In situ detection of matrix metalloproteinase-2 (MMP2) and the metalloproteinase inhibitor TIMP2 transcripts in human primary hepatocellular carcinoma and in liver metastasis. J Hepatol 1997;26:593-605

Nakamura $\mathrm{R}$, Kataoka $\mathrm{H}$, Sato $\mathrm{N}$, Kanamori M, Ihara M, Igarashi H, Ravshanov S, Wang YJ, Li ZY, Shimamura T, Kobayashi T, Konno H, Shinmura K, Tanaka M, Sugimura H. EPHA2/EFNA1 expression in human gastric cancer. Cancer Sci 2005;96:42-7

Nam SW, Park JY, Ramasamy A, Shevade S, Islam A, Long PM, Park CK, Park SE, Kim SY, Lee SH, Park WS, Yoo NJ, Liu ET, Miller LD, Lee JY. Molecular changes from dysplastic nodule to hepatocellular carcinoma through gene expression profiling. Hepatology 2005;42:809-18

Okabe H, Satoh S, Kato T, Kitahara O, Yanagawa R, Yamaoka Y, Tsunoda T, Furukawa Y, Nakamura Y. Genomewide analysis of gene expression in human hepatocellular carcinomas using cDNA microarray: identification of genes involved in viral carcinogenesis and tumor progression. Cancer Res 2001;61:2129-37

Okuda K. Hepatocellular carcinoma. J Hepatol 2000;32(1 Suppl):225-37

Parkin DM, Bray F, Ferlay J, Pisani P. Global cancer statistics, 2002. CA Cancer J Clin 2005;55:74-108

Pilarsky C, Wenzig M, Specht T, Saeger HD, Grutzmann R. Identification and validation of commonly overexpressed genes in solid tumors by comparison of microarray data. Neoplasia 2004;6:744-50

Ree AH, Tvermyr M, Engebraaten O, Rooman M, Rosok O, Hovig E, Meza-Zepeda LA, Bruland OS, Fodstad O. Expression of a novel factor in human breast cancer cells with metastatic potential. Cancer Res 1999;59:4675-80

Reeves HL, Narla G, Ogunbiyi O, Haq Al, Katz A, Benzeno S, Hod E, Harpaz N, Goldberg S, Tal-Kremer S, Eng FJ, Arthur MJ, Martignetti JA, Friedman SL. Kruppel-like factor 6 (KLF6) is a tumor-suppressor gene frequently inactivated in colorectal cancer. Gastroenterology 2004;126:1090-103

Sakamoto M, Hirohashi S, Shimosato Y. Early stages of multistep hepatocarcinogenesis: adenomatous hyperplasia and early hepatocellular carcinoma. Hum Pathol 1991;22: 172-8

Sampath J, Long PR, Shepard RL, Xia X, Devanarayan V, Sandusky GE, Perry WL, Dantzig AH, Williamson M, Rolfe M, Moore RE. Human SPF45, a splicing factor, has limited expression in normal tissues, is overexpressed in many tumors, and can confer a multidrug-resistant phenotype to cells. Am J Pathol 2003;163:1781-90

Schafer H, Trauzold A, Sebens T, Deppert W, Folsch UR, Schmidt WE. The proliferation-associated early response gene p22/PRG1 is a novel p53 target gene. Oncogene 1998;16:2479-87

Seimiya M, O-Wang J, Bahar R, Kawamura K, Wang Y, Saisho H, Tagawa M. Stage-specific expression of Clast6/ E3/LAPTM5 during B cell differentiation: elevated expres- sion in human B lymphomas. Int J Oncol 2003;22:301-4

Semov A, Moreno MJ, Onichtchenko A, Abulrob A, Ball M, Ekiel I, Pietrzynski G, Stanimirovic D, Alakhov V. Metastasisassociated protein S100A4 induces angiogenesis through interaction with Annexin II and accelerated plasmin formation. J Biol Chem 2005;280:20833-41

Shen J, Li C, Gudas LJ. Regulation of the laminin beta 1 (LAMB1), retinoic acid receptor beta, and bone morphogenetic protein 2 genes in mutant F9 teratocarcinoma cell lines partially deficient in cyclic AMP-dependent protein kinase activity. Cell Growth Differ 1997;8:1297-304

Sherman M, Peltekian KM, Lee C. Screening for hepatocellular carcinoma in chronic carriers of hepatitis $B$ virus: incidence and prevalence of hepatocellular carcinoma in a North American urban population. Hepatology 1995;22: 432-8

Shirota Y, Kaneko S, Honda M, Kawai HF, Kobayashi K. Identification of differentially expressed genes in hepatocellular carcinoma with cDNA microarrays. Hepatology 2001;33:832-40

Stoecklin G, Gross B, Ming XF, Moroni C. A novel mechanism of tumor suppression by destabilizing $A U$-rich growth factor mRNA. Oncogene 2003;22:3554-61

Tanaka T, Akatsuka S, Ozeki M, Shirase T, Hiai H, Toyokuni $S$. Redox regulation of annexin 2 and its implications for oxidative stress-induced renal carcinogenesis and metastasis. Oncogene 2004;23:3980-9

Villalonga P, Guasch RM, Riento K, Ridley AJ. RhoE inhibits cell cycle progression and Ras-induced transformation. Mol Cell Biol 2004;24:7829-40

Weterman MA, Stoopen GM, van Muijen GN, Kuznicki J, Ruiter DJ, Bloemers HP. Expression of calcyclin in human melanoma cell lines correlates with metastatic behavior in nude mice. Cancer Res 1992;52:1291-6

Wirths O, Waha A, Weggen S, Schirmacher P, Kuhne T, Goodyer CG, Albrecht S, Von Schweinitz D, Pietsch T. Overexpression of human Dickkopf-1, an antagonist of wingless/WNT signaling, in human hepatoblastomas and Wilms' tumors. Lab Invest 2003;83:429-34

Xi S, Dyer KF, Kimak M, Zhang Q, Gooding WE, Chaillet JR, Chai RL, Ferrell RE, Zamboni B, Hunt J, Grandis JR. Decreased STAT1 expression by promoter methylation in squamous cell carcinogenesis. J Natl Cancer Inst 2006;98: 181-9

Zaman SN, Melia WM, Johnson RD, Portmann BC, Johnson PJ, Williams R. Risk factors in development of hepatocellular carcinoma in cirrhosis: prospective study of 613 patients. Lancet 1985;1:1357-60

Zhao Y, Oberley TD, Chaiswing L, Lin SM, Epstein CJ, Huang TT, St Clair D. Manganese superoxide dismutase deficiency enhances cell turnover via tumor promoter-induced alterations in AP-1 and p53-mediated pathways in a skin cancer model. Oncogene 2002;21:3836-46 